\title{
Dynamics of soil organic carbon stock in a typical catchment of the Loess Plateau: comparison of model simulations with measurements
}

\author{
Xing Wu • Anu Akujärvi • Nan Lu • Jari Liski • \\ Guohua Liu · Yafeng Wang • Maria Holmberg • \\ Fei Li $\cdot$ Yuan Zeng $\cdot$ Bojie Fu
}

Received: 28 April 2014/Accepted: 19 October 2014/Published online: 1 November 2014

(C) Springer Science+Business Media Dordrecht 2014

\begin{abstract}
Land use changes are known to significantly affect the soil $\mathrm{C}$ balance by altering both $\mathrm{C}$ inputs and losses. Since the late 1990s, a large area of the Loess Plateau has undergone intensive land use changes during several ecological restoration projects to control soil erosion and combat land degradation, especially in the Grain for Green project. By using remote sensing techniques and the Yasso07 model, we simulated the dynamics of soil organic carbon (SOC) stocks in the Yangjuangou catchment of the Loess Plateau. The performance of the model was evaluated by comparing the simulated results with the intensive
\end{abstract}

X. Wu $\cdot$ N. Lu · G. Liu · Y. Wang · B. Fu $(\bowtie)$

State Key Laboratory of Urban and Regional Ecology, Research Center for Eco-environmental Sciences (RCEES), Chinese Academy of Sciences, Beijing 100085, China

e-mail: bfu@rcees.ac.cn

$\mathrm{X} . \mathrm{Wu}$

e-mail: xingwu@rcees.ac.cn

A. Akujärvi · J. Liski · M. Holmberg

Finnish Environment Institute (SYKE), Natural

Environment Centre, Ecosystem Processes, P.O. Box 140, 00251 Helsinki, Finland

\section{F. Li}

Nanjing Institute of Geography and Limnology, Chinese Academy of Sciences, Nanjing 210008, China

\section{Y. Zeng}

Institute of Remote Sensing and Digital Earth, Chinese Academy of Sciences, Beijing 100094, China field measurements in 2006 and 2011 throughout the catchment. SOC stocks and NPP values of all land use types had generally increased during our study period. The average SOC sequestration rate in the upper $30 \mathrm{~cm}$ soil from 2006 to 2011 in the Yangjuangou catchment was approximately $44 \mathrm{~g} \mathrm{C} \mathrm{m}^{-2} \mathrm{yr}^{-1}$, which was comparable to other studies in the Loess Plateau. Forest and grassland showed a more effective accumulation of SOC than the other land use types in our study area. The Yasso07 model performed reasonably well in predicting the overall dynamics of SOC stock for different land use change types at both the site and catchment scales. The assessment of the model performance indicated that the combination of Yasso07 model and remote sensing data could be used for simulating the effect of land use changes on SOC stock at catchment scale in the Loess Plateau.

Keywords Soil organic carbon · Modeling · Land use change $\cdot$ Carbon sequestration $\cdot$ Loess Plateau

\section{Introduction}

Globally, soils store approximately 2,300 Pg carbon (C) which is at least three times greater than the atmospheric $\mathrm{C}$ pool and twice as large as the biomass C pool (Jobbágy and Jackson 2000). Thus, even a slight change in soil $\mathrm{C}$ stock may have a considerable effect on atmospheric $\mathrm{CO}_{2}$ concentration and global 
climate (Davidson and Janssens 2006). Land use change and management practices have been shown to affect the soil $\mathrm{C}$ balance significantly by altering both C inputs and losses (Post and Kwon 2000; Guo and Gifford 2002; Wu et al. 2010; Karhu et al. 2012). In recent decades, human activities, such as deforestation, intensified crop cultivation and afforestation, have resulted in substantial changes in land use globally ( $\mathrm{Lu}$ et al. 2013). Although a number of studies have been carried out in determining the soil $\mathrm{C}$ balance induced by land use change at regional and national scales (Piao et al. 2009; Tuomi et al. 2009; Zhang et al. 2013), the dynamics of soil C stock following human disturbances remain unclear, which might be due to the high inherent natural variability in soils and variable dynamics of soil $\mathrm{C}$ under different land use change types.

The Loess Plateau, which covers approximately $62.4 \times 10^{4} \mathrm{~km}^{2}$, is the largest continuous area of loess in the world. It is well-known for its long agricultural history and severe soil erosion (Shi and Shao 2000; Wang et al. 2011). Since the late 1990s, several ecological restoration projects have been conducted in the Loess Plateau aiming to control soil erosion and combat land degradation, such as the Grain for Green (GFG) project. Approximately 14.67 million hectares (Mha) of sloped cropland and 17.33 Mha of barren land were replanted within the GFG project from 1999 to 2010 (Wang et al. 2012). Thus, the land use in this region has changed dramatically and soil erosion has decreased substantially after the implementation of the GFG project (Chen et al. 2007; Fu et al. 2011). These changes in turn will have profound effects on soil $\mathrm{C}$ stock and its dynamics, and it is therefore valuable to measure the spatial and temporal variations in soil $\mathrm{C}$ stock due to the afforestation.

Owing to the high spatial variability of soil C stocks and high uncertainty in their temporal dynamics, and because measuring these soil $\mathrm{C}$ variables is laborious and expensive, soil $\mathrm{C}$ models are widely used to estimate soil $\mathrm{C}$ stocks and their dynamics at different scales (e.g. Peng et al. 2002; Karhu et al. 2011; Palosuo et al. 2012). However, there are several kinds of dynamic soil $\mathrm{C}$ models available varying in terms of model complexity and requirements of input information (Liski et al. 2005; Peltoniemi et al. 2007). Some of these models are process-oriented and characterize soil $\mathrm{C}$ dynamics at a relatively detailed level, and therefore require detailed input information. However, such detailed information is not easily accessible, especially over large extents, which limits the widespread application of these models (Tuomi et al. 2011a). Compared with some process-oriented soil C models, such as CENTURY (Parton et al. 1987) and RothC (Coleman and Jenkinson 1999), the Yasso07 model has been successfully applied and validated at regional (Karhu et al. 2012; Palosuo et al. 2012), national (Ortiz et al. 2013) and global scales (Tuomi et al. 2009) by using relatively limited input information. Some of the required information, such as the quantity and chemical quality of $\mathrm{C}$ input to soil during the entire simulation period, is not always available, however, particularly for regions without long-term soil survey or comprehensive forest inventory.

Net primary production (NPP), the net flow of C from the atmosphere into plants, is the primary source of $\mathrm{C}$ in soils (Field et al. 1995). Understanding the dynamics of soil $\mathrm{C}$ stocks, therefore, depends on reliable estimates of NPP and the proportion of the NPP entering the soil (Bolinder et al. 2007; Zhao and Luo 2008). An estimate of the $C$ inputs from plant residues to the soil can be obtained by subtracting the quantities of $\mathrm{C}$ removed from the plant-soil system in harvested and removed biomass from NPP (Koga et al. 2011). Compared with the information of $C$ input to soil as required by the Yasso07 model, the spatial patterns of NPP changes are relatively easy to acquire and quantify by using ecosystem production models in concert with remote sensing techniques (Field et al. 1995). Since the C inputs from plant residues to the soil can vary significantly among different land use types, regional NPP estimation might provide additional information related to the $\mathrm{C}$ inputs to soil for the Yasso07 model.

In this study, we simulated the dynamics of soil organic carbon (SOC) stocks by using Yasso07 with carbon input derived by the CASA model in a typical catchment of the Loess Plateau. The simulated results were compared with the intensive field measurements of SOC in 2006 and 2011 throughout the catchment. The objectives of this study were (1) to quantify the changes of SOC stock due to the GFG project in the Yangjuangou catchment of the Loess Plateau, (2) to investigate the performance of an approach based on the Yasso07 model in predicting SOC stock dynamics in response to different land use change types, and (3) 

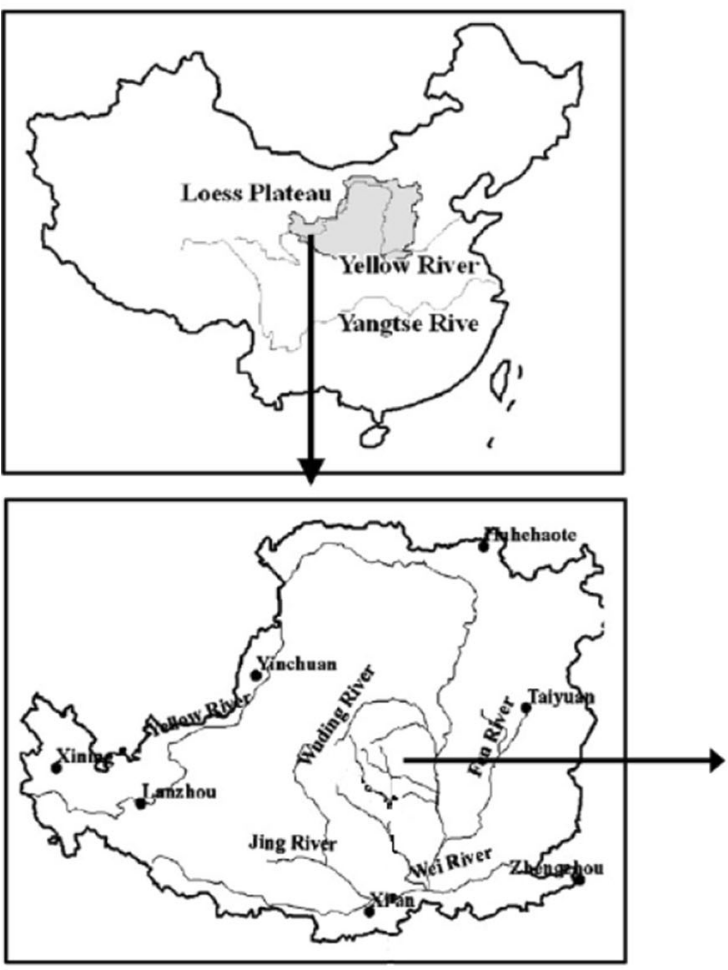

Fig. 1 Location of the study area and sampling sites

to test the applicability of the Yasso07 at the catchment scale using NPP as C input.

\section{Materials and methods}

Study area

The Yangjuangou catchment $\left(36^{\circ} 42^{\prime} \mathrm{N}, 109^{\circ} 31^{\prime} \mathrm{E}\right)$ is located in the center of the Loess Plateau in northern Shaanxi Province of China (Fig. 1). The catchment has a total area of $2.02 \mathrm{~km}^{2}$ and the elevation ranges from 1,050 to $1,298 \mathrm{~m}$. It is a typical gully and hilly area with a gully density of $2.74 \mathrm{~km} \mathrm{~km}^{-2}$. The area has a semi-arid continental climate with an average annual rainfall of $535 \mathrm{~mm}$. The rainfall is mainly concentrated between July and September with large inter-annual variations (Fig. 2). The soil in the study area is mainly derived from loess with a texture

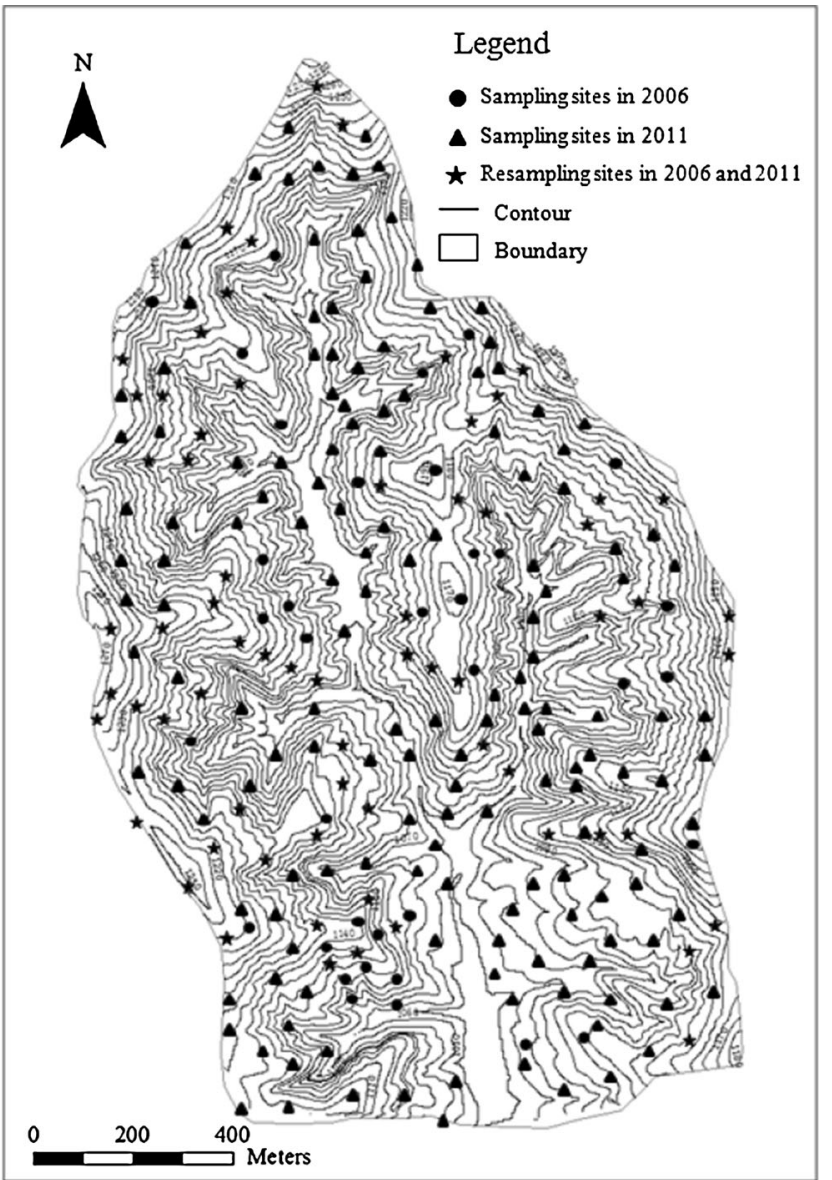

ranging from fine silt to silt and vulnerable to erosion (Wang et al. 2011). Most of the cropland on steep slopes were abandoned or replanted after 1998 as a result of the GFG project. Now, forest (dominated by Robinia pseudoacacia), grassland (Artemisia sacrorum, Stipa bungeana, and Artemisia scoparia) and shrubland (Prunus armeniaca and Hippophae rhamnoides) are the main land use types in this area (Yao et al. 2013).

Soil sampling and analysis

In order to account for spatial heterogeneity, soil samples were collected from 103 sampling sites throughout the Yangjuangou catchment according to different topographic positions and land use types during 7th-15th July 2006. At least four different positions from top, middle and bottom of the slops were sampled for each land use type. A portable GPS 
Fig. 2 Climate data (1969-2011) used as input in the Yasso07 model

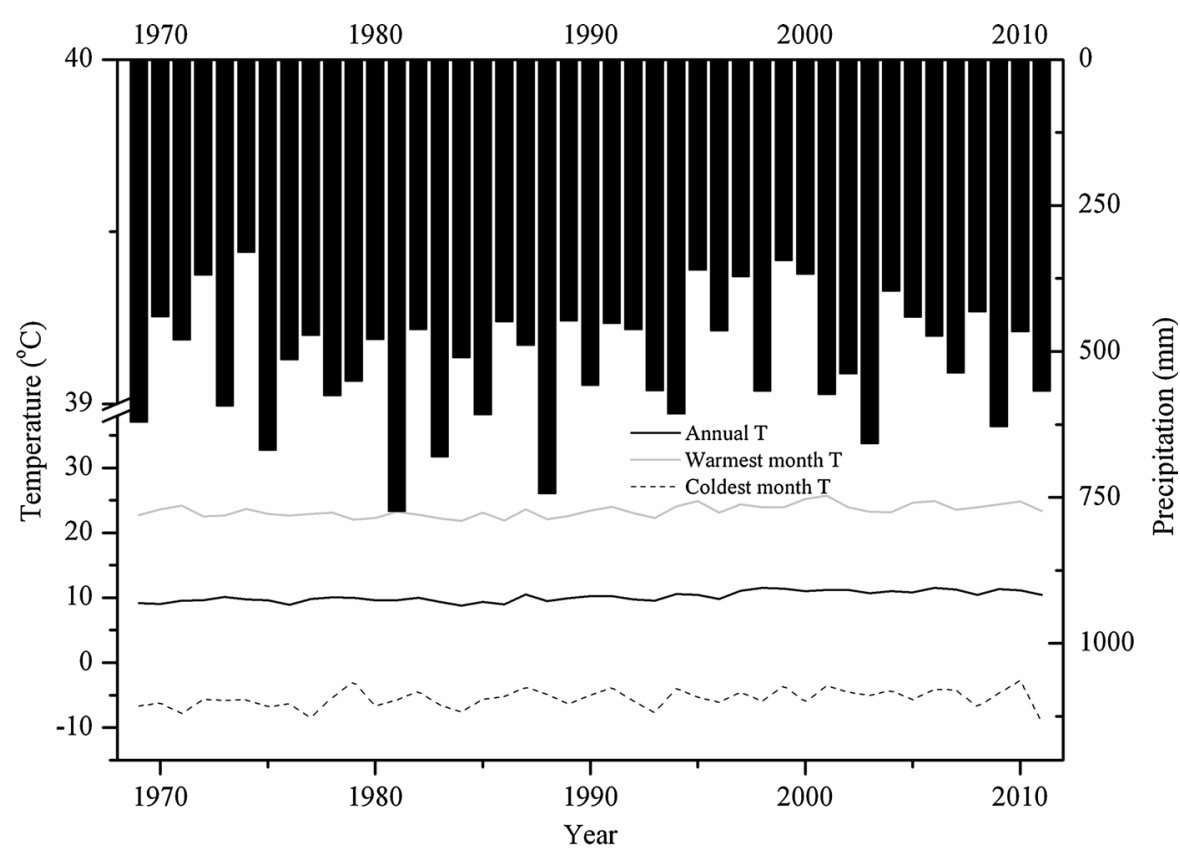

receiver was used to locate the sampling sites (Fig. 1). Soil was sampled to a $30 \mathrm{~cm}$ depth with a soil core auger (Eijkelkamp, diameter $6 \mathrm{~cm}$ ), and divided in $0-5,5-10,10-20$ and $20-30 \mathrm{~cm}$ intervals. Three replicated samples were homogenized by hand mixing and were sieved for the determination of SOC after being air-dried (Wang et al. 2011).

The second intensive soil sampling was performed during 9th-24th July 2011 when 210 sampling sites were selected in the catchment in order to carry out further experiments (Yao et al. 2013). As we did in 2006, all land use types and typical topography types in the catchment were involved and each land use/ topography type contained at least eight sampling points in 2011 to account for spatial heterogeneity with more uniform sampling distribution. The distance between neighboring sites ranged from 50 to $100 \mathrm{~m}$ (Fig. 1). Within these 210 sites, 64 sampling sites were sampled both in 2006 and 2011. These resampled sites were used to compare the average yearly change of measured and simulated SOC stocks in this study. The soil sampling strategy and processing method were the same as in 2006. The fraction of SOC $\left(\mathrm{SOC}_{i}\right)$ in a given soil depth was determined by using the potassiumdichromate oxidation method (Wang et al. 2011). Soil $\mathrm{C}$ stock $\left(\mathrm{kg} \mathrm{C} \mathrm{m}^{-2}\right)$ of the upper $30 \mathrm{~cm}$ was estimated as the sum of the products of $\mathrm{SOC}_{i}\left(\mathrm{~g} \mathrm{~kg}^{-1}\right)$, bulk density $\left(\mathrm{g} \mathrm{cm}^{-3}\right)$ and soil layer thickness $\mathrm{D}_{i}(\mathrm{~m})$.

Aerial photograph interpretation and field survey techniques were used to classify land use types in 1998 (Fu et al. 2000). The main land use types occurring in our study area were cropland, mature forest, immature forest (planted after 1998), shrubland, orchard, grassland and sloped cropland. The land use maps of the Yangjuangou catchment in 2006 and 2011 were derived from 10-m resolution ALOS satellite images. Esri ArcGIS 10.0 (Esri, Relands, CA) was used for land use change analysis and spatial interpolation of SOC stocks. The ordinary kriging interpolation method was used to produce the spatial distribution maps of SOC stock in the study area. The value of variable $\mathrm{Z}$ at the unsampled location $\mathrm{x}_{0}, \mathrm{Z}\left(\mathrm{x}_{0}\right)$ is estimated based on the data from the surrounding locations, $\mathrm{Z}\left(\mathrm{x}_{i}\right)$, as

$Z\left(x_{0}\right)=\sum_{i=1}^{n} w_{i} \times Z\left(x_{i}\right)$

where $w_{i}$ is the weight assigned to each $\mathrm{Z}\left(\mathrm{x}_{i}\right)$ value and $n$ is the number of the closest neighboring sampled locations used for estimation. The weights are calculated by estimating the spatial structure of the variable's distribution represented by a sample variogram as 
$\gamma(h)=\frac{1}{2 n} \sum_{i=1}^{n}\left[Z\left(x_{i}\right)-Z\left(x_{i}+h\right)\right]^{2}$

where $\mathrm{x}_{i}$ and $\mathrm{x}_{i}+h$ are sampling locations separated by a distance $h, n$ is the number of pairs of sample locations, and $\mathrm{Z}\left(\mathrm{x}_{i}\right)$ and $\mathrm{Z}\left(\mathrm{x}_{i}+h\right)$ are the observed values of variable $\mathrm{Z}$ at the corresponding locations.

Model simulations

We simulated the dynamics of SOC in the Yangjuangou catchment from 1998 to 2011 using the Yasso07 soil carbon model (Tuomi et al. 2009, 2011a, b). When initializing the model we assumed that the SOC was in a steady state with the litter input from the vegetation in 1998. To test the suitability of the modeling approach to a regional application, we simulated the pool and temporal trend of SOC in the sampling sites in 2006 ( $n=103), 2011(n=210)$ and in the ones sampled both in 2006 and $2011(n=64)$. We investigated the validity of the simulated estimates by comparing them to the measured estimates of the pool of SOC in 2006 and 2011 and the change in this pool between 2006 and 2011. The SOC stock and the changes in the catchment were simulated by running the model for each $30 \times 30 \mathrm{~m}$ pixel of the study area. We evaluated the performance of our approach at site and catchment scales by comparing the simulated estimates to the measured ones in the main land use change types.

In the Yasso07 soil carbon model, it is assumed that litter consists of four compound groups, namely compounds 1) soluble in a non-polar solvent, ethanol or dichloromethane (denoted using E), 2) soluble in water (W), 3) hydrolysable in acid (A) and 4) neither soluble nor hydrolysable at all (N). The decomposition rates of these compound groups depend on temperature and precipitation. The decomposition of the compound groups results in mass flows both out of the system and between the compound groups and, in addition, formation of more recalcitrant humus $(\mathrm{H})$. The decomposition of woody litter depends additionally on its diameter (Tuomi et al. 2011b). We used the same parameter values of the model in this study as were used in a previous site scale application in the same area (Lu et al. 2013). The simulated estimates represented SOC in the topmost $1 \mathrm{~m}$ deep soil layer.

Model input data

\section{Net primary production}

Net primary production (NPP) was calculated based on the Carnegie-Ames-Stanford Approach (CASA) biosphere model introduced by Potter et al. (1993). For a given area, the NPP $\left(\mathrm{g} \mathrm{C} \mathrm{m}^{-2}\right)$ at a grid cell is a product of the amount of photosynthetically active radiation absorbed by green vegetation (APAR) and the light use efficiency $(\varepsilon)$, by which that radiation is converted to plant biomass increment.

$N P P=A P A R \times \varepsilon$

The $\varepsilon$ for each pixel is the product of the maximal light use efficiency $\left(\varepsilon_{\max }\right)$, and the scalars representing the suitability of temperature $\left(T_{1}, T_{2}\right)$ and the availability of water $(W)$ (Potter et al. 1993):

$\varepsilon(x, t)=T_{1}(x, t) \times T_{2}(x, t) \times W(x, t) \times \varepsilon_{\max }$

The two temperature scalars $\left(T_{1}, T_{2}\right)$ attempt to capture two aspects of the regulation of plant growth by temperature. The water scalar $(W)$ is calculated in a monthly time step as a function of the ratio of estimated evapotranspiration to potential evapotranspiration. The specific functions of $T_{1}$, $T_{2}$ and $W$ could be found in $\mathrm{Yu}$ et al. (2009). The $\varepsilon_{\max }$ for different land use types in our study were estimated according to the Zhu et al. (2006) and Yu et al. (2009) (Table 1).

For each pixel, CASA calculates APAR as the product of surface solar irradiance $S$ in units of $\mathrm{MJ} \mathrm{m}^{-2}$, a factor of 0.5 , which represents the fraction of surface solar irradiance, and the fraction of photosynthetically active radiation absorbed by green vegetation (FPAR), which is calculated based on the normalized difference vegetation index (NDVI)

$F P A R(x, t)=\frac{\left(N D V I(x, t)-N D V I_{i, \min }\right) \times\left(F P A R_{\max }-F P A R_{\min }\right)}{\left(N D V I_{i, \text { max }}-N D V I_{i, \min }\right)}+F P A R_{\min }$ 
Table 1 The maximal light use efficiency $\left(\varepsilon_{\max }\right)$, the fraction of carbon input harvested, the fraction of non-woody litter and the quality of non-woody and woody litter for different land use types

\begin{tabular}{|c|c|c|c|c|c|c|c|c|c|c|c|c|}
\hline \multirow[t]{3}{*}{ Land use type } & \multirow{3}{*}{$\begin{array}{l}\varepsilon_{\max } \\
\left(\mathrm{g} \mathrm{C} \mathrm{MJ}^{-1}\right)\end{array}$} & \multirow{3}{*}{$\begin{array}{l}\text { Fraction } \\
\text { of carbon } \\
\text { harvested }\end{array}$} & \multirow{3}{*}{$\begin{array}{l}\text { Fraction of } \\
\text { non-woody } \\
\text { litter }\end{array}$} & \multicolumn{9}{|c|}{ Proportions of AWEN fractions } \\
\hline & & & & \multicolumn{4}{|c|}{ Non-woody litter } & \multicolumn{5}{|c|}{ Woody litter } \\
\hline & & & & A & W & $\mathrm{E}$ & $\mathrm{N}$ & A & W & $\mathrm{E}$ & $\mathrm{N}$ & $\begin{array}{l}\text { Diameter } \\
(\mathrm{cm})\end{array}$ \\
\hline Cropland & 0.608 & 0.5 & 1 & 0.385 & 0.200 & 0.367 & 0.048 & 0.385 & 0.200 & 0.367 & 0.048 & 0 \\
\hline Sloped cropland & 0.608 & 0.5 & 1 & 0.385 & 0.200 & 0.367 & 0.048 & 0.385 & 0.200 & 0.367 & 0.048 & 0 \\
\hline Grassland & 0.541 & 0.0 & 1 & 0.394 & 0.185 & 0.356 & 0.065 & 0.394 & 0.185 & 0.356 & 0.065 & 0 \\
\hline Shrubland & 0.541 & 0.1 & 0.91 & 0.450 & 0.170 & 0.090 & 0.290 & 0.719 & 0.081 & 0.012 & 0.188 & 3 \\
\hline Immature forest & 0.490 & 0.0 & 0.91 & 0.450 & 0.170 & 0.090 & 0.290 & 0.719 & 0.081 & 0.012 & 0.188 & 3 \\
\hline Mature forest & 0.490 & 0.0 & 0.91 & 0.450 & 0.170 & 0.090 & 0.290 & 0.719 & 0.081 & 0.012 & 0.188 & 3 \\
\hline Orchard & 0.541 & 0.1 & 0.91 & 0.450 & 0.170 & 0.090 & 0.290 & 0.719 & 0.081 & 0.012 & 0.188 & 3 \\
\hline
\end{tabular}

derived from remote sensing data. The relationship between NDVI and FPAR is nearly linear and has been defined by Eq. (5) (Potter et al. 1993; Ruimy and Saugier 1994; Zhu et al. 2006):

where $F P A R_{\max }(=0.950)$ and $F P A R_{\min }(=0.001)$ are the maximal and minimal FPAR, respectively and are independent of vegetation type. (NDVI) $i$, min and $(\mathrm{NDVI})_{i, \max }$ are the statistical minimal and maximal NDVI values of vegetation type $i$ and represent bare and full cover with the vegetation type $i$, respectively. The algorithms for $(\mathrm{NDVI})_{i, \min }$ and (NDVI) $i$, max have been described by Zhu et al. (2006) and Yu et al. (2009). The yearly estimates of NPP $\left(\mathrm{g} \mathrm{C} \mathrm{m}^{-2} \mathrm{yr}^{-1}\right)$ were added up from the monthly NPP for 5 years (i.e. 1998, 2003, 2006, 2009 and 2011) by using multitemporal Landset TM/ETM data. In between those years, NPP values were estimated by linear interpolation.

\section{Carbon input from different land use types}

We calculated the carbon input to the model based on the estimated NPP of different land use types. The litter production of vegetation for model input was calculated according to the NPP values and the harvested fraction of different land use types. We assumed that none of the NPP was harvested in grassland, mature forest and immature forest, and applied a 0.10 harvest ratio for shrubland and orchard and 0.50 for cropland and sloped cropland (Table 1). The fraction of non-woody litter was assumed to be one in cropland, sloped cropland and grassland, and
0.91 in the other land use types. For the chemical quality of litter, in terms of the AWEN composition the Yasso07 model uses, we applied values based on literature (Adamopoulos et al. 2005; Jensen et al. 2005; Lu et al. 2013, Table 1). The diameter of woody litter in mature forest, immature forest, shrubland and orchard was assumed to be $3 \mathrm{~cm}$ (Lu et al. 2013).

The annual carbon input was assumed to be equal to NPP in the areas without land use change between 1998 and 2011. Because litters were usually removed during the restoration activities, the carbon input was set to zero in the first year of land use change, assuming the previous litter mass was totally removed when planting the new vegetation. The annual carbon input from the next year to 2011 were estimated based on biomass accumulation and litter turnover rates by Eq. (6):

$$
\begin{aligned}
\text { Cinput }_{i}= & T R_{A} \times \sum_{i=1}^{n} A N P P \times\left(1-T R_{A}\right)^{i-n}+T R_{B} \\
& \times \sum_{i=1}^{n} B N P P \times\left(1-T R_{B}\right)^{i-n}
\end{aligned}
$$

where Cinput $_{i}$ was the carbon input of the $i$ th year. $A N P P$ and $B N P P$ were aboveground and belowground NPP, respectively. $T R_{A}$ and $T R_{B}$ were turnover rates of above and belowground biomass, respectively. The ratio of ANPP to BNPP was estimated to be $1: 3$ for grassland, and 4:1 for forest, shrubland and orchard. The $T R_{A}$ was estimated to be 1.0 for grassland, and 0.10 for other land use types, and the $T R_{B}$ was estimated to be 0.15 for all land use types (Zhang and Liang 2002; Zhang and Shangguan 2005). 


\section{Climate}

The climate data (1969-2011) were obtained from the Yan'an weather station, which is the nearest station (approximately $10 \mathrm{~km}$ ) to our study area. The average values of precipitation, mean annual temperature and temperature amplitude (the difference between the average temperatures of the warmest and the coldest month) were calculated as climate input to the Yasso07 model (Fig. 2). We used mean values of the years 1969-1998 for calculating the initial SOC pool and yearly values for the actual simulation from 1998 to 2011.

Statistical analyses and model performance

Statistical analyses were carried out with SPSS 13.0 and SigmaPlot 2000 (SPSS Inc., Chicago, USA). Significant differences in the NPP and measured SOC stocks among different land use types and years were determined using one-way ANOVA and MANOVA analysis.

The model performance was evaluated quantitatively by comparing the means of the observed and predicted values using regression analysis (regression coefficient, $R^{2}$ ), root mean square error (RMSE), model efficiency $(M E)$ and normalized mean root square error (NRMSE, \%) (Loague and Green 1991; Janssen and Heuberger 1995; Karhu et al. 2012):

$$
\begin{aligned}
& R M S E=\left[\frac{1}{n} \sum_{i=1}^{n}\left(P_{i}-O_{i}\right)^{2}\right]^{1 / 2} \\
& M E=1-\left[\sum_{i=1}^{n}\left(P_{i}-O_{i}\right)^{2} / \sum_{i=1}^{n}\left(O_{i}-\bar{O}\right)^{2}\right]
\end{aligned}
$$

$$
N R M S E=R M S E / \bar{O} \times 100
$$

where $P_{i}$ are the predicted values, $O_{i}$ are the observed values, $\bar{O}$ is the mean of the observed data and $n$ is the number of samples. RMSE is a measure for the mean error between the observations and the model simulations. $M E$, which ranges from one to negative infinity, is a measure of how efficiently the model reproduces the observations relative to the mean of the observations (Janssen and Heuberger 1995). The $M E$ is the better the closer to a maximum value of one it is. However, negative $M E$ indicates that the predicted values are a worse estimator than using the mean of the observations (Loague and Green 1991). The model residuals were calculated by subtracting the modeled SOC stocks from the measured values.

\section{Results}

NPP and measured SOC stocks

Mature and immature forests had the highest levels of annual mean NPP, followed by shrubland, grassland and orchard throughout the period from 1998 to 2011 (Table 2). The NPP values of sloped cropland and cropland were significantly lower than those of the other land use types $(P<0.05)$. The increased NPP in afforested land cover types is most likely related to enhanced growth of trees as a result of the GFG project. The area of sloped cropland has decreased and that of immature forest and shrubland increased substantially since 1998 (Fig. 3). All the sloped croplands were replanted before 2006 in this catchment. During the growth of the newly planted forest, the NPP values increased gradually during 1998-2011 (Table 2). The NPP values in 1998 and 2003 were significantly lower than in the other years, resulting in large variation among these years. Besides the afforestation, climate variation and crop rotation with different species might have contributed to the fluctuations of NPP during our study period.

The SOC stocks in the soil profile of $0-30 \mathrm{~cm}$ were distributed variably under different land use types (Table 3). Similar to the NPP, the SOC stock of mature forest was significantly higher than that of the other land use types in both 2006 and $2011(P<0.05)$. The SOC stocks of cropland were $0.95 \pm 0.23 \mathrm{~kg} \mathrm{C} \mathrm{m}^{-2}$ in 2006 and $1.07 \pm 0.05 \mathrm{~kg} \mathrm{C} \mathrm{m}^{-2}$ in 2011, respectively, which were 41.1 and $59.8 \%$ lower than those of mature forest. Generally, SOC stocks of all land use types increased in the Yangjuangou catchment during 2006-2011. However, statistical differences $(P<0.05)$ were only observed in forest and grassland (Table 3), indicating that SOC accumulated more effectively in forest and grassland than in the other land use types. The average SOC stock of 0-30 $\mathrm{cm}$ soil layer in all land use types was $1.36 \pm 0.03 \mathrm{~kg} \mathrm{C} \mathrm{m}^{-2}$ in 2011, which was significantly higher than the value $\left(1.14 \pm 0.03 \mathrm{~kg} \mathrm{C} \mathrm{m}^{-2}\right)$ in 2006 . Based on these different SOC stocks between 2006 and 2011, we estimated that the SOC sequestration rate was approximately $44 \mathrm{~g} \mathrm{C} \mathrm{m}^{-2} \mathrm{yr}^{-1}$ for the whole catchment. 


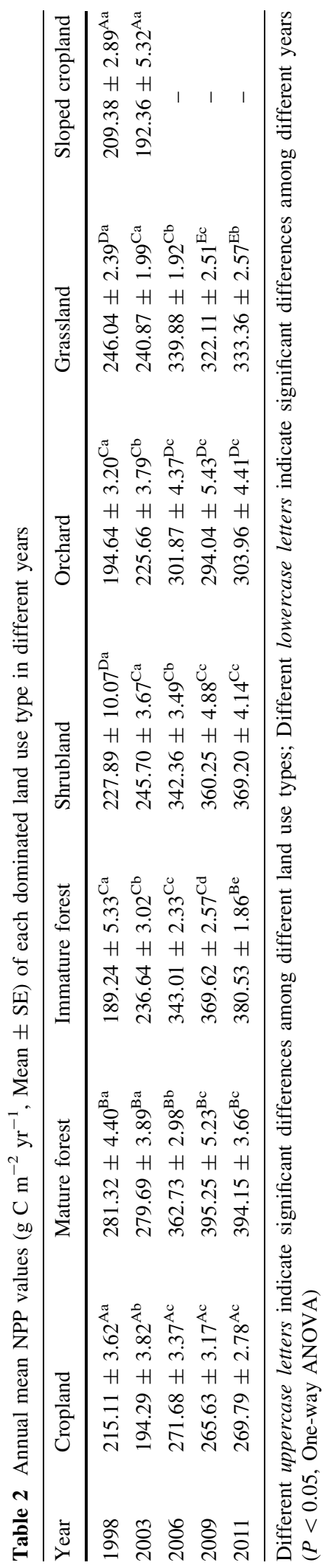

The two-way ANOVA analysis showed that land use type has significant impact on NPP $(P<0.001)$. However, the effects of year and the interaction between land use type and year on NPP were not significant $(P>0.05$, Table 4$)$. The two-way ANOVA also indicated that SOC stocks varied significantly with different land use types and sampling years $(P<0.001)$, whereas there was no significant interaction between land use and year on SOC stocks $(P=0.351)$. The spatial distribution of SOC stocks in the Yangjuangou catchment in 2006 and 2011, estimated using the ordinary kriging interpolation method, was closely related to land use distribution (Figs. 3, 4). High SOC stocks were located usually in forest, shrubland and grassland. In the whole catchment, the SOC stocks were higher in the north than in the south (Fig. 4) since the southern area has become the base of food supplies under intensified cultivation activities after the implementation of the GFG project.

Simulated SOC stocks and the model performance at the site scale

The Yasso07 model predicted the overall increase in the SOC stocks well when compared to the measurements at sampling sites (Fig. 5). The correlation coefficients $\left(R^{2}\right)$ between the model simulations and the measurement results were 0.359 in 2006 and 0.200 in 2011, respectively. The modeled SOC stocks in both years were generally 3-5 times higher than the measured stocks (Fig. 5). It was expected that the modeled stocks were higher because they represented the top $1 \mathrm{~m}$ layer whereas the measurements were for the top $30 \mathrm{~cm}$ only. We evaluate the difference in more detail in the "Discussion" section (see "Model performance" section).

Besides the magnitude of the SOC stock, the Yasso07 model also predicted well the direction of the SOC stock changes for the main land use change types (Fig. 6). The average yearly changes of simulated SOC stock for all land use change types were in the same order as measured. Based on the RMSE and ME values, the predicted SOC stock changes were in good agreement with the measured values (Table 5). The model slightly overestimated the SOC stock change in the case of grassland or shrubland converted to forest during 2006-2011 (Fig. 6a). For the sites where grassland was 

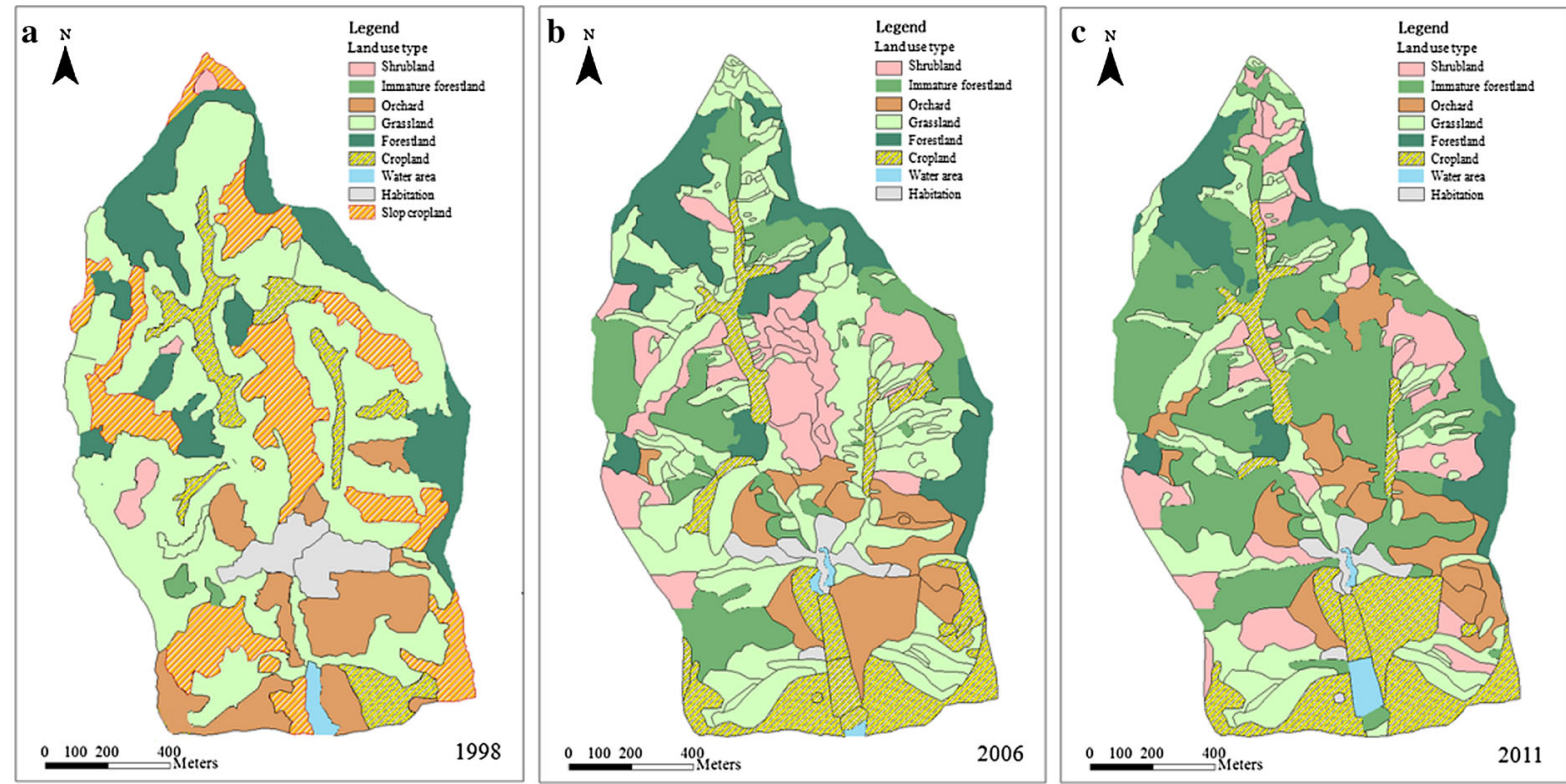

Fig. 3 Land use map of the Yangjuangou catchment in 1998 (a), 2006 (b) and 2011 (c)

converted to shrubland, cropland or shrubland to orchard and the sites without land use change, the simulated and measured values were closely correlated, but the model underestimated the SOC stock change (Fig. 6; Table 5).

Simulated SOC stocks and the model performance at the catchment scale

We simulated the SOC stocks and the changes in the Yangjuangou catchment by running the Yasso07 model for each $30 \times 30 \mathrm{~m}$ pixel of the whole study area. These predicted values were compared to the spatially interpolated results of the measured SOC stocks by each pixel in 2006 and 2011 (Fig. 7). Generally, the simulated SOC stocks were significantly correlated with the spatial interpolation of the measurements at the catchment scale in both 2006 and $2011(P<0.001)$. Similar to the results at the site scale, due to the different soil depths involved in our measurements and simulations, the magnitude of the predicted SOC stocks was usually 3-5 times higher than the measured stocks.

The model predicted reasonably well the dynamics of SOC stocks for different land use change types during 2006-2011 in the whole catchment. Both modeled and measured results showed that conversion from grassland or shrubland to forest, from grassland to shrubland and from cropland to grassland clearly increased the SOC stocks (Fig. 8). Conversion from grassland or shrubland to cropland and forest to grassland generally resulted in a significant decrease in SOC stock according to both the simulation and the measurement results. According to the $M E$ value and the average model residual, the model showed an excellent fit to the measured SOC stock when results from all pixels were included, and a positive $M E$ value (0.712) indicates that the SOC dynamics could be well captured by the model (Table 6). The SOC stock changes during conversion from cropland to grassland were slightly overestimated by the Yasso07 model at the catchment scale. In contrast, the model marginally underestimated the SOC stock change in the case of changing grassland to shrubland and changing grassland or shrubland to cropland based on the RMSE and $M E$ values (Table 6). Negative values of $M E$ suggest that the model did not capture the temporal dynamics correctly for these land use change types.

\section{Discussion}

Dynamics of SOC stock

This study investigated the dynamics of SOC stock for different land use types during 2006-2011 in a typical 
catchment of the Loess Plateau. Our results showed that land use types exhibit significant effect on SOC stock, which is consistent with previous studies (Guo and Gifford 2002; Wang et al. 2011; Zhang et al. 2013). The land use patterns were well matched with the spatial distribution of SOC stocks within the study area in 2006 and 2011, demonstrating that land use type might be an important factor influencing the spatial variation in SOC stock. In our study, forest exhibited the highest SOC stock in the 0-30 cm depth, followed by shrubland, grassland and orchard. The lowest SOC stock was found in cropland, indicating that replacing cropland with alternative cover could improve SOC sequestration. These results were in agreement with a previous study in our study area (Wang et al. 2011). The lower SOC stock in cropland might be attributed to the severe soil erosion and the reduced residue input to the soil, and is supported by the relatively low NPP values in this study.

SOC content and stock were found to be significantly affected by land use change. However, the dynamics of SOC following land use conversion vary greatly with previous land use, management practices and other biophysical conditions (Jobbágy and Jackson 2000; Karhu et al. 2012, Wang et al. 2012). The establishment of either grassland or lands with perennial vegetation on degraded cropland has been proposed as an effective method for climate change mitigation since these land use types could increase SOC content and stock (Lu et al. 2013; Heikkinen et al. 2014). In contrast, soil loses its organic carbon into the atmosphere following the cultivation of the land that was previously covered by perennial vegetation (Karhu et al. 2011; Ding et al. 2013). In our study area, the land use and landscape were dramatically changed after the implementation of the GFG project. A large area of sloped cropland and cropland was replanted since 1998, resulting in a significant increase of SOC stock in the whole catchment (Wang et al. 2011). Our measurements showed that converting grassland to forest or shrubland, and cropland to grassland increased the SOC stocks, whereas a decrease of SOC stock was found when forest was converted to grassland and grassland or shrubland converted to cropland in the southern part of the catchment. This might be partly due to the differences in the amount of litter fall and root biomass, vegetation coverage and human disturbance (DeGryze et al. 2004). Moreover, most of the sites without land use change from 2006 to 
Table 4 Results ( $P$-values) of two-way ANOVA concerning the effects of land use type, year, and their interactions on NPP and SOC stocks

\begin{tabular}{lrr}
\hline & \multicolumn{1}{c}{ NPP } & \multicolumn{1}{c}{ SOC } \\
\hline Land use type & $<0.001$ & $<0.001$ \\
Year & 0.068 & $<0.001$ \\
Land use type $\times$ Year & 0.493 & 0.351 \\
\hline
\end{tabular}

2011 also showed a substantial increase of SOC, suggesting that the ecological succession of vegetation after replantation had a significant effect on SOC sequestration as well. This could be evidenced by the gradual increase in NPP values for the most of land use type, especially for the newly planted forest.

According to our measurements, the average SOC sequestration rate in the upper $30 \mathrm{~cm}$ soil from 2006 to 2011 in this catchment was approximately $44 \mathrm{~g} \mathrm{C} \mathrm{m}^{-2}$ $\mathrm{yr}^{-1}$, which was slightly higher than observed in a previous study in this study area, which coved the period from 1998 to 2006 (Wang et al. 2011). However, relatively low SOC sequestration rate or even a decrease of SOC in the first few years following afforestation has been frequently reported and attributed to the reduced litter inputs and enhanced decomposition rates compared to those prior to conversion (Karhu et al. 2011; Wang et al. 2012; Lu et al. 2013). Nevertheless, our results were

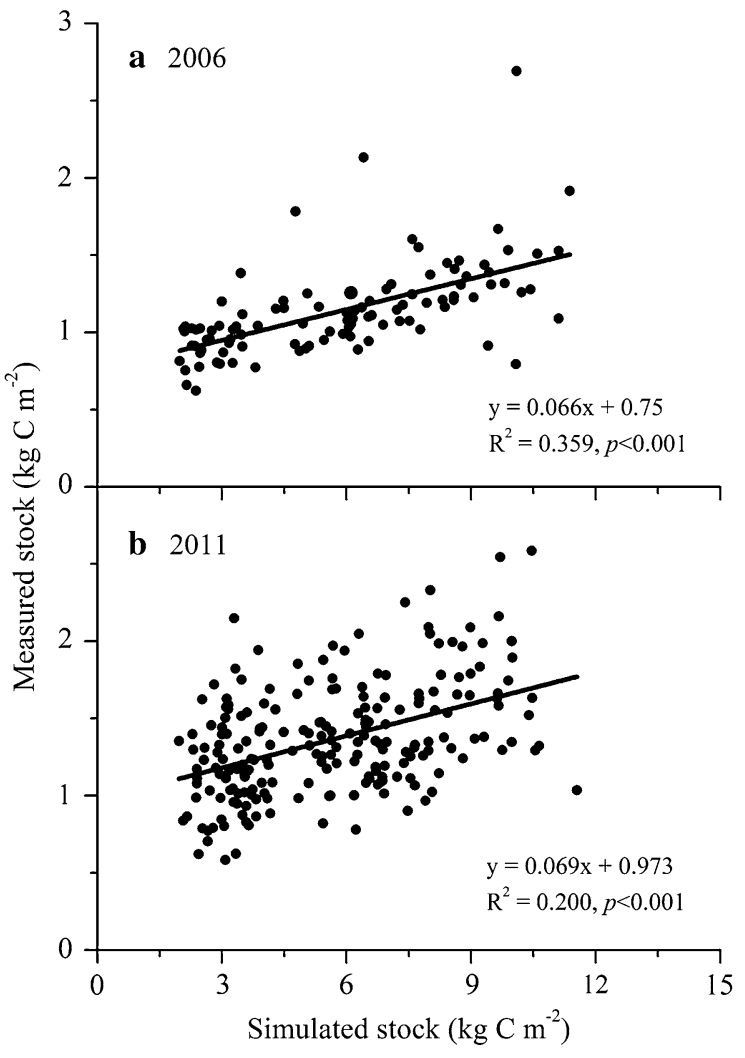

Fig. 5 Correlations between measured and simulated SOC stocks in sampling sites in 2006, a $(n=103)$ and 2011, b $(n=210)$
Fig. 4 SOC stock distribution in the Yangjuangou catchment in 2006 (a) and 2011 (b)
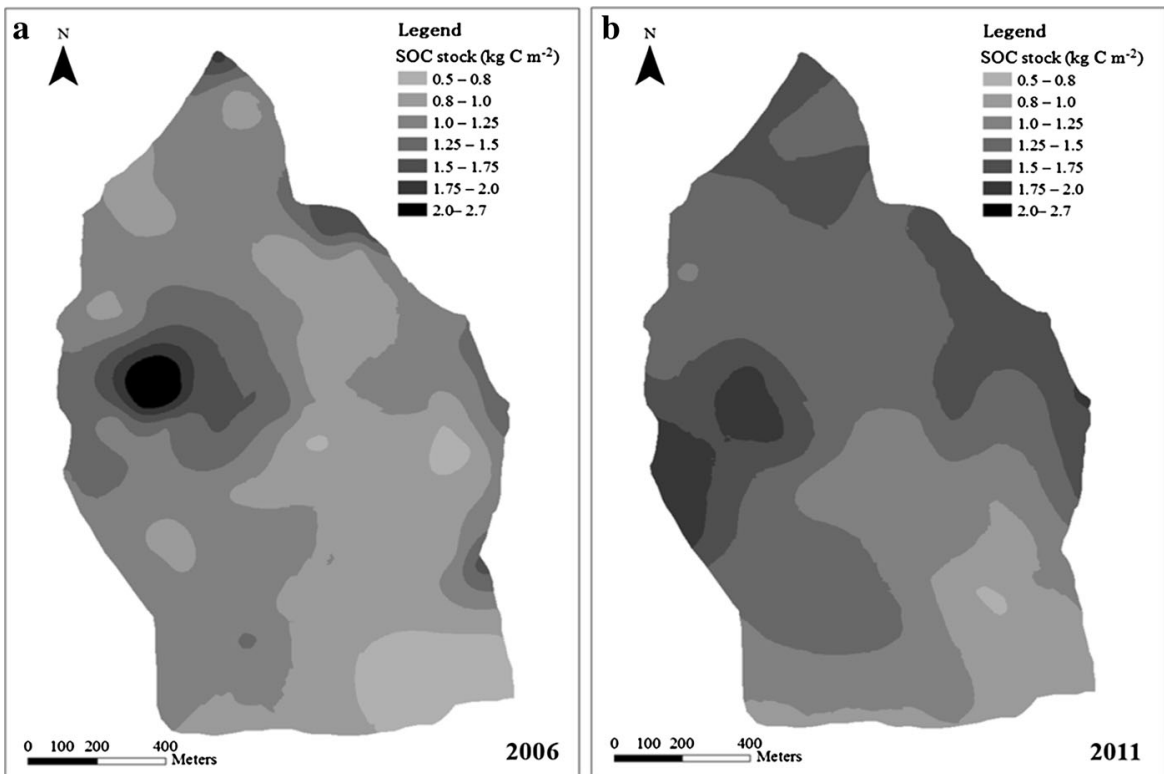
Fig. 6 Average yearly changes of measured and simulated SOC stock in sampling sites for main land use change types:

a grassland/shrubland to forest $(n=9)$, b grassland to shrubland $(n=6)$, c cropland/shrubland to orchard $(n=5)$, d without land use change $(n=42)$ and $\mathbf{e}$ all data $(n=64)$ during 2006 and 2011

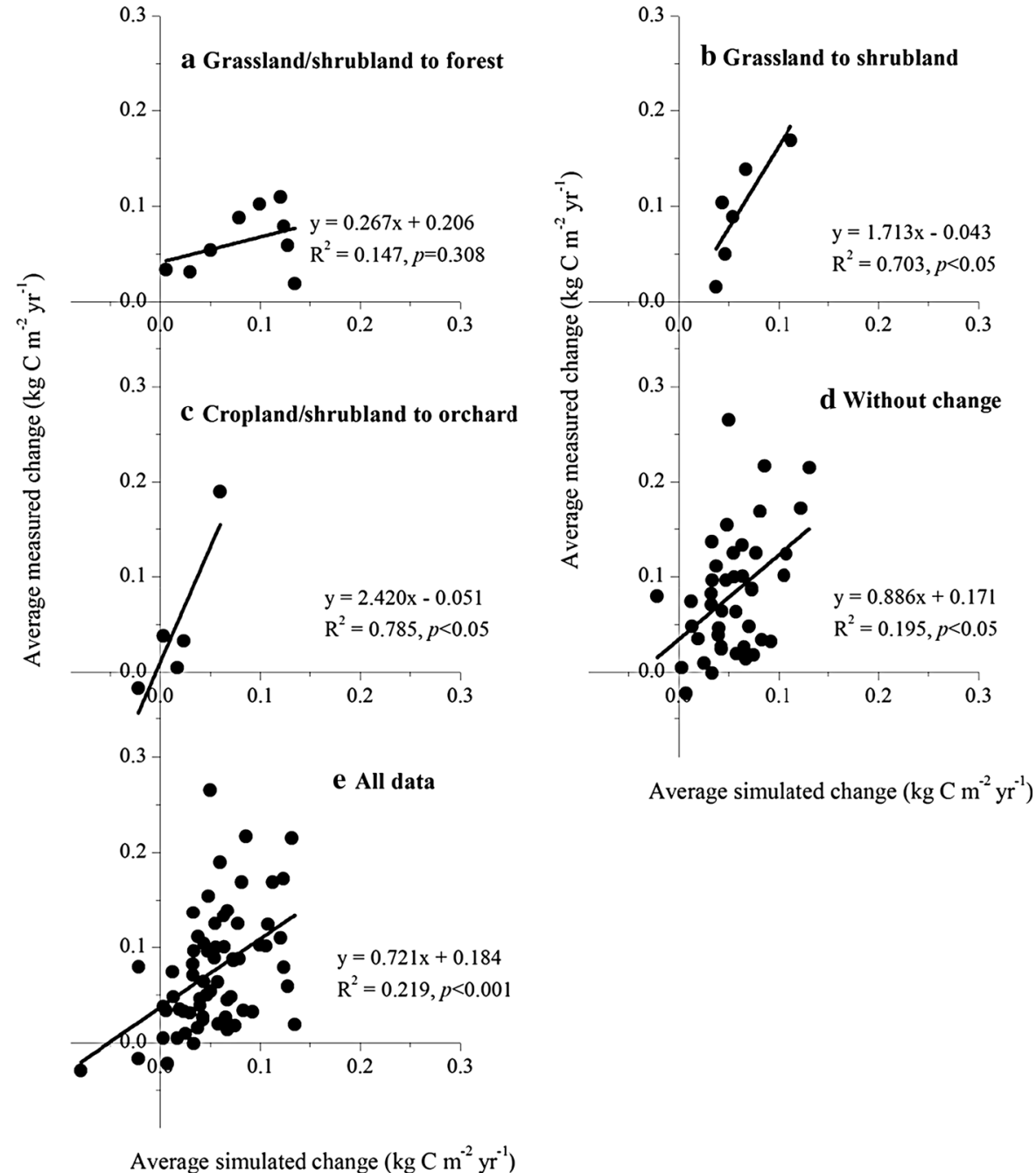

Table 5 Model performance at sampling sites estimated for main land use change types according to root mean square error (RMSE), model efficiency (ME), normalized RMSE (NRMSE, given as \% of observed mean) and average model residuals

\begin{tabular}{llrrr}
\hline Land use change type & $\begin{array}{l}\text { RMSE } \\
\left(\mathrm{kg} \mathrm{C} \mathrm{m}^{-2}\right)\end{array}$ & ME & NRMSE (\%) & Average residuals $\left(\mathrm{kg} \mathrm{C} \mathrm{m}^{-2}\right)$ \\
\hline Grassland/shrubland to forest & 0.241 & -1.448 & 75.30 & -0.106 \\
Grassland to shrubland & 0.239 & 0.138 & 50.70 & 0.171 \\
Cropland/shrubland to orchard & 0.304 & 0.305 & 92.36 & 0.166 \\
Without land use change & 0.317 & -0.005 & 77.29 & 0.140 \\
All data & 0.297 & 0.061 & 78.23 & 0.108 \\
\hline
\end{tabular}

comparable to the average SOC sequestration rate in the top $20 \mathrm{~cm}$ soil for the whole GFG project in China, approximately 33 to $37 \mathrm{~g} \mathrm{C} \mathrm{m}^{-2} \mathrm{yr}^{-1}$ (Zhang et al. 2010; Deng et al. 2014), and similar to the results from adjacent catchments within the Loess Plateau (Wang et al. 2012; Zhang et al. 2013).
Model performance

Generally, the Yasso07 model, using the $\mathrm{C}$ input derived by the CASA model, predicted the overall dynamics of SOC stock reasonably well at both the site and catchment scales. The modeled stock estimates 


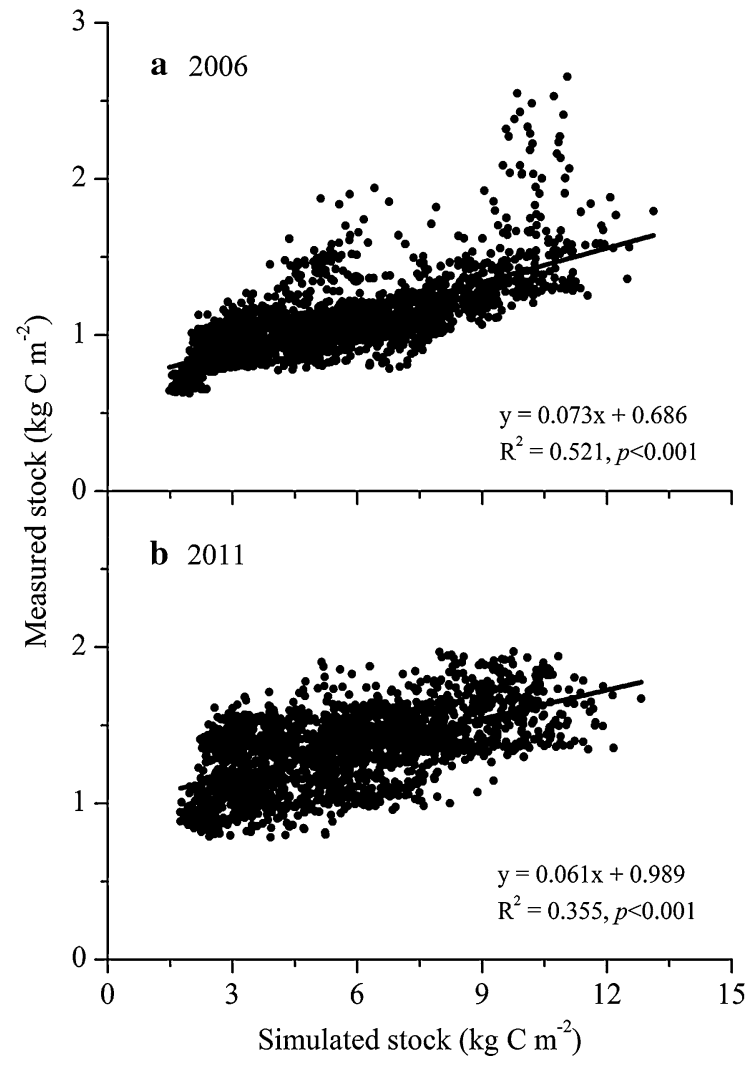

Fig. 7 Correlations between measured and simulated SOC stocks in pixels of the whole study area in 2006 a $(n=2,148)$ and $2011 \mathbf{b}(n=2,148)$

representing the top $1 \mathrm{~m}$ layer were approximately 3-5 times higher than the measured estimates representing a shallower top $30 \mathrm{~cm}$ layer. The results from Zhang et al. (2013), who reported SOC stocks in $5 \mathrm{~m}$ deep soil of ten land use types in a catchment adjacent to our study area, showed that the SOC stocks in the uppermost $1 \mathrm{~m}$ layer were also about 3-5 times higher than those in the upper $30 \mathrm{~cm}$ soil. This comparison suggests that the SOC stocks predicted by Yasso07 in this study were comparable to the measurements in other study within the Loess Plateau. However, it is still possible that the modeling overestimated the soil carbon stocks to some extent because there is no information to carry out a more detailed comparison.

In addition to the magnitude of the SOC stock in the study area, our approach based on the Yasso07 model and the CASA model predicted the observed changes in SOC stocks in response to different land use change types quite well. According to RMSE and $M E$ values,
Yasso07 predicted the SOC stock change reasonably well for most of the land use change types, indicating that the model could accurately calculate the litter decomposition based on the AWEN composition in different land use types. The slight overestimation of SOC stock during conversion from cropland to grassland might be partly due to the lack of consideration of soil erosion during our simulation. Previous studies showed that soil erosion can lead to substantial soil C loss in the Loess Plateau (Shi and Shao 2000; Fu et al. 2011). In addition, although the organic amendment and fertilizer were found to affect the development of soil C stock (Karhu et al. 2012), the effect of fertilization on soil $\mathrm{C}$ sequestration was not included for the cropland during the modeling, which could be one of the reasons for the underestimation of SOC stock change in the case of changing grassland or shurbland to cropland.

Karhu et al. (2011) demonstrated that the Yasso07 model can be applied for estimating soil C stock dynamics due to land use change in boreal conditions. Heikkinen et al. (2014) also found that the Yasso07 model performed well in estimating soil $\mathrm{C}$ stock changes during the 30 -years period after cropland conversion to grassland in Russian temperate zone. Moreover, the dynamics of SOC following afforestation of cropland at six sites under different climatic conditions in the Loess Plateau during 1980-2010 were simulated by the Yasso07 model, and the performance was well validated by field measurements (Lu et al. 2013). In this study, we simulated the dynamic of SOC stocks during 2006-2011 by using Yasso07 and NPP derived by remote sensing in a typical catchment of the Loess Plateau. The modeled average SOC sequestration rate in the $1 \mathrm{~m}$ soil layer from 2006 to 2011 for the whole catchment was about $39.8 \mathrm{~g} \mathrm{C} \mathrm{m}^{-2} \mathrm{yr}^{-1}$, which was lower than Deng et al.'s (2014) result of $75 \mathrm{~g} \mathrm{C} \mathrm{m}^{-2} \mathrm{yr}^{-1}$, an average soil sequestration rate of the whole GHG project. However, our model simulations were comparable to the results reported by Feng et al. (2013), who estimated the mean soil $\mathrm{C}$ stock increase to be about $10 \mathrm{~g} \mathrm{C} \mathrm{m}^{-2} \mathrm{yr}^{-1}$ in the $0-50 \mathrm{~cm}$ soils from 2000-2008 by using remote sensing techniques and ecosystem modeling as we did in this study. Therefore, our results suggested that the combination of Yasso07 model and remotely sensed data could be used for simulating the effect of land use changes on SOC stock at the catchment scale in the Loess Plateau. 
Fig. 8 Average yearly changes of measured and simulated SOC stock in pixels for main land use change types: a grassland/ shrubland to forest $(n=250)$, b grassland to shrubland $(n=25)$, c cropland/shrubland to orchard $(n=29)$, d grassland/shrubland to cropland ( $n=33)$, e forest to grassland $(n=81)$, f cropland to grassland $(n=48)$, $\mathbf{g}$ without land use change $(n=1,677)$ and h all data $(n=2,148)$ during 2006 and 2011

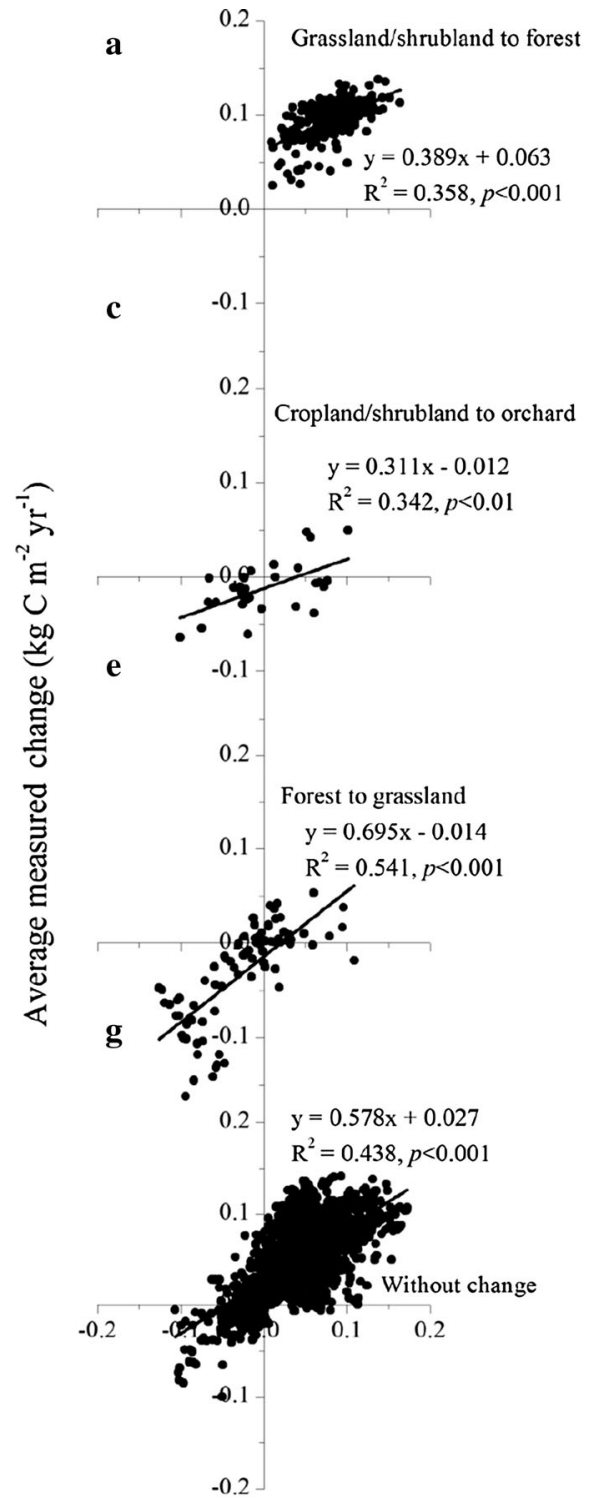

Average simulated change $\left(\mathrm{kg} \mathrm{C} \mathrm{m}^{-2} \mathrm{yr}^{-1}\right)$

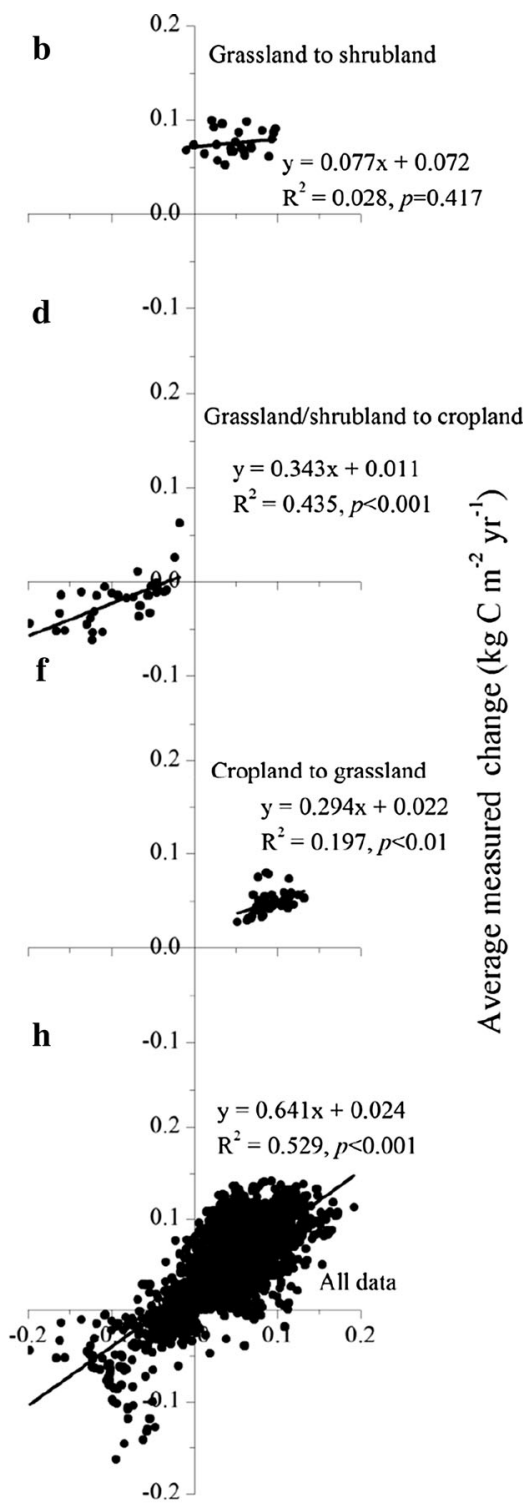

Average simulated change $\left(\mathrm{kg} \mathrm{C} \mathrm{m}{ }^{-2} \mathrm{yr}^{-1}\right)$
Uncertainties of the study

Although our simulation results are satisfactory, there are substantial uncertainties related to the prediction of SOC stock dynamics in this study. Firstly, we assumed that the SOC was in a steady state with the litter input from the vegetation in 1998 during the initialization process, as is often done in soil $\mathrm{C}$ modeling studies (Karhu et al. 2012; Ortiz et al. 2013). Although agricultural soils are known to lose $\mathrm{C}$ due to intensive management practices (Shi and Shao 2000), the Loess Plateau has a very long agricultural history and initializing the model with the 1998 litter input is thus justified. Secondly, we assumed that the spatial variations of climatic variables (precipitation and temperature), as required by Yasso07 model, in this small catchment $\left(2.02 \mathrm{~km}^{2}\right)$ were not significant. Therefore, the modeling was performed using the same climate information for the whole catchment, and the different simulated SOC stocks arise mainly from particular litter turnover and $\mathrm{C}$ input of each pixel and varying litter quality in each land use type. The precision of the $\mathrm{C}$ input depends greatly on the reliability of the CASA model and the quality of the 
Table 6 Model performance at catchment scale estimated for main land use change types according to root mean square error (RMSE), model efficiency (ME), normalized RMSE (NRMSE, given as \% of observed mean) and average model residuals

\begin{tabular}{llcrc}
\hline Land use change type & $\begin{array}{l}\text { RMSE } \\
\left(\mathrm{kg} \mathrm{C} \mathrm{m}^{-2}\right)\end{array}$ & ME & NRMSE (\%) & $\begin{array}{c}\text { Average residuals } \\
\left(\mathrm{kg} \mathrm{C} \mathrm{m}^{-2}\right)\end{array}$ \\
\hline Grassland/shrubland to forest & 0.151 & -1.377 & 31.73 & 0.073 \\
Grassland to shrubland & 0.196 & -8.105 & 51.71 & 0.129 \\
Cropland/shrubland to orchard & 0.219 & -1.557 & -341.42 & -0.064 \\
Grassland/shrubland to cropland & 0.396 & -9.393 & -375.97 & 0.352 \\
Forest to grassland & 0.196 & 0.424 & -117.31 & -0.022 \\
Cropland to grassland & 0.228 & -16.693 & 94.07 & -0.213 \\
Without land use change & 0.173 & 0.138 & 68.53 & 0.048 \\
All data & 0.179 & 0.712 & 70.52 & 0.047
\end{tabular}

remote sensing data (Xing et al. 2010; Feng et al. 2013). However, the dynamics of soil carbon stock induced by physical processes (e.g. soil erosion) were not considered during our simulation, which might be a weakness in our study and may warrant further study. Thirdly, although some previous studies pointed out that the changes in soil C stocks can be modeled based on quality and quantity of $\mathrm{C}$ inputs and climate data alone (Karhu et al. 2011, 2012; Heikkinen et al. 2014), we believe that the changes of soil properties (e.g. soil moisture and soil texture) during land use conversion might have effects on soil $\mathrm{C}$ dynamic. Lastly, the soil SOC stock measurements are greatly uncertain due to spatial variability of soil $\mathrm{C}$ and errors introduced by sampling and laboratory analysis (Goidts et al. 2009). In addition, some uncertainties might also come from the linear interpolation of NPP for some years and the spatial interpolation of SOC stocks in the whole catchment.

\section{Conclusions}

Our results support the view that replanting degraded cropland in the Loess Plateau due to the GFG project improved SOC sequestration and therefore contributed greatly to the climate change mitigation. With replanting, the NPP values of most land use types increased gradually during 1998-2011. Based on our measurements, land use change showed a significant effect on SOC stocks. The average SOC sequestration rate in the uppermost $30 \mathrm{~cm}$ soil layer in the Yangjuangou catchment was approximately $44 \mathrm{~g} \mathrm{C} \mathrm{m}^{-2} \mathrm{yr}^{-1}$ between 2006 and 2011, which was comparable to other studies in the Loess Plateau. Therefore, the GFG project should have a strong positive contribution to SOC sequestration in the Loess Plateau and China. The Yasso07 model performed well in predicting the overall dynamics of SOC stock for different land use change types at both the site and catchment scales. Moreover, the evaluation of the model performance suggested that the combination of Yasso07 model and remotely sensed data could be used for simulating the effect of land use changes on SOC stock at the catchment scale in the Loess Plateau. However, more long-term studies and further validation are needed to reduce the uncertainties associated with the application of the Yasso07 model at different scales.

Acknowledgments This study was supported by the Strategic Priority Research Program of the Chinese Academy of Sciences (XDA05060103), the Ministry of Science and Technology of China (2012CB417103), the National Natural Science Foundation of China (41105117), the Cooperation Program of the Chinese Academy of Sciences (GJHZ1215) and the Academy of Finland (256231). Special thanks go to Yao Xueling and Liu Yu for helping spatial analysis. We also thank the anonymous reviewers for constructive comments on the previous version of the manuscript.

\section{References}

Adamopoulos S, Voulgaridis E, Passialis C (2005) Variation of certain chemical properties within the stemwood of black locust (Robinia pseudoacacia L.). Holz Roh Werkst 63:327-333

Bolinder MA, Janzen HH, Gregorich EG, Angers DA, VandenBygaart AJ (2007) An approach for estimating net primary productivity and annual carbon inputs to soil for common agricultural crops in Canada. Agric Ecosyst Environ 118:29-42

Chen LD, Gong J, Fu BJ, Huang ZL, Huang YL, Gui LD (2007) Effect of land use conversion on soil organic carbon sequestration in the loess hilly area, Loess Plateau of China. Ecol Res 22:641-648 
Coleman K, Jenkinson DS (1999) RothC-26.3. A model for the turnover of carbon in the soil. Model description and windows user's guide. IACR-Rothamsted, Harpenden, p 47

Davidson EA, Janssens IA (2006) Temperature sensitivity of soil carbon decomposition and feedbacks to climate change. Nature 440:165-173

DeGryze S, Six J, Paustian K, Morris SJ, Paul EA, Merckx R (2004) Soil organic carbon pool changes following landuse conversions. Global Change Biol 10:1120-1132

Deng L, Liu G, Shangguan Z (2014) Land use conversion and changing soil carbon stocks in China's 'Grain-for-Green' program: a synthesis. Global Change Biol. doi:10.1111/ gcb.12508

Ding F, Hu Y, Li L, Li A, Shi S, Lian P, Zeng D (2013) Changes in soil organic carbon and total nitrogen stocks after conversion of meadow to cropland in Northeast China. Plant Soil 373:659-672

Feng XM, Fu BJ, Lu N, Zeng Y, Wu BF (2013) How ecological restoration alters ecosystem services: an analysis of carbon sequestration in China's Loess Plateau. Sci Rep. doi:10. 1038/srep02846

Field CB, Randerson JT, Malmstrom CM (1995) Global net primary production: combining ecology and remote-sensing. Remote Sens Environ 51:74-88

Fu BJ, Chen LD, Ma KM, Zhou HF, Wang J (2000) The relationships between land use and soil conditions in the hilly area of the loess plateau in northern Shaanxi, China. Catena 39:69-78

Fu BJ, Liu Y, Lü YH, He CS, Zeng Y, Wu BF (2011) Assessing the soil erosion control service of ecosystems change in the Loess Plateau of China. Ecol Complex 8:284-293

Goidts E, van Wesemael B, Crucifix M (2009) Magnitude and sources of uncertainties in soil organic carbon (SOC) stock assessments at various scales. Eur J Soil Sci 60:723-739

Guo LB, Gifford RM (2002) Soil carbon stocks and land use change: a meta analysis. Global Change Biol 8:345-360

Heikkinen J, Kurganova I, de Gerenyu VL, Palosuo T, Regina K (2014) Changes in soil carbon stock after cropland conversion to grassland in Russian temperate zone: measurements versus model simulation. Nutr Cycl Agroecosyst 98:97-106

Janssen PHM, Heuberger PSC (1995) Calibration of processoriented models. Ecol Model 83:55-66

Jensen LS, Salo Y, Palmason F, Breland TA, Henriksen TM, Stenberg B, Pedersen A, Lundstro C, Esala M (2005) Influence of biochemical quality on $\mathrm{C}$ and $\mathrm{N}$ mineralisation from a broad variety of plant materials in soil. Plant Soil 273:307-326

Jobbágy EG, Jackson RB (2000) The vertical distribution of soil organic carbon and its relation to climate and vegetation. Ecol Appl 10:423-436

Karhu K, Wall A, Vanhala P, Liski J, Esala M, Regina K (2011) Effects of afforestation and deforestation on boreal soil carbon stocks-Comparison of measured C stocks with Yasso07 model results. Geoderma 164:33-45

Karhu K, Gärdenäs AI, Heikkinen J, Vanhala P, Tuomi M, Liski J (2012) Impacts of organic amendments on carbon stocks of an agricultural soil-Comparison of model-simulations to measurements. Geoderma 189:606-616

Koga N, Smith P, Yeluripati JB, Shirato Y, Kimura SD, Nemoto $M$ (2011) Estimating net primary production and annual plant carbon inputs, and modelling future changes in soil carbon stocks in arable farmlands of northern Japan. Agric Ecosyst Environ 144:51-60

Liski J, Palosuo T, Peltoniemi M, Sievänen R (2005) Carbon and decomposition model Yasso for forest soils. Ecol Model 189:168-182

Loague K, Green RE (1991) Statistical and graphical methods for evaluating solute transport models: overview and application. J Contam Hydrol 7:51-74

Lu N, Liski J, Chang RY, Akujärvi A, Wu X, Jin TT, Wang YF, Fu BJ (2013) Soil organic carbon dynamics of black locust plantations in the middle Loess Plateau area of China. Biogeosciences 10:7053-7063

Ortiz CA, Liski J, Gärdenäs AI, Lehtonen A, Lundblad M, Stendahl J, Agren GI, Karltun E (2013) Soil organic carbon stock changes in Swedish forest soils-A comparison of uncertainties and their sources through a national inventory and two simulation models. Ecol Model 251:221-231

Palosuo T, Foereid B, Svensson M, Shurpali N, Lehtonen A, Herbst M, Linkosalo T, Ortiz C, Todorovic GR, Marcinkonis S, Li C, Jandl R (2012) A multi-model comparison of soil carbon assessment of a coniferous forest stand. Environ Modell Softw 35:38-49

Parton WJ, Schimel DS, Cole CV, Ojima D (1987) Analysis of factors controlling soil organic matter levels in Great Plains grasslands. Soil Sci Soc Am 51:1173-1179

Peltoniemi M, Thürig E, Ogle SM, Palosuo T, Shrumpf M, Wützler T, Butterbach-Bahl K, Chertov OG, Komarov AS, Mikhailov AV, Gärdenäs A, Perry C, Liski J, Smith P, Mäkipää R (2007) Models in country scale carbon accounting of forest soils. Silva Fenn 41:575-602

Peng C, Jiang H, Apps MJ, Zhang Y (2002) Effects of harvesting regimes on carbon and nitrogen dynamics of boreal forests in central Canada: a process model simulation. Ecol Model 155:177-189

Piao S, Fang J, Ciais P, Peylin P, Huang Y, Sitch S, Wang T (2009) The carbon balance of terrestrial ecosystems in China. Nature 458:1009-1013

Post WM, Kwon KC (2000) Soil carbon sequestration and land use change: processes and potential. Global Change Biol 6:317-327

Potter CS, Randerson JT, Field CB, Matson PA, Vitousek PM, Mooney HA, Klooster SA (1993) Terrestrial ecosystem production: a process model based on global satellite and surface data. Global Biogeochem Cycles 7:811-841

Ruimy A, Saugier B (1994) Methodology for the estimation of terrestrial net primary production from remotely sensed data. J Geophys Res 97:18515-18521

Shi H, Shao M (2000) Soil and water loss from the Loess Plateau in China. J Arid Environ 45:9-20

Tuomi M, Thum T, Järvinen H, Fronzek S, Berg B, Harmon M, Trofymow JA, Sevanto S, Liski J (2009) Leaf litter decomposition-Estimates of global variability based on Yasso07 model. Ecol Model 220:3362-3371

Tuomi M, Rasinmäki J, Repo A, Vanhala P, Liski J (2011a) Soil carbon model Yasso07 graphical user interface. Environ Modell Softw 26:1358-1362

Tuomi M, Laiho R, Repo A, Liski J (2011b) Wood decomposition model for boreal forests. Ecol Model 222:709-718 
Wang YF, Fu BJ, Lü YH, Chen LD (2011) Effects of vegetation restoration on soil organic carbon sequestration at multiple scales in semi-arid Loess Plateau, China. Catena 85:58-66

Wang Z, Liu GB, Xu MX, Zhang J, Wang Y, Tang L (2012) Temporal and spatial variations in soil organic carbon sequestration following revegetation in the hilly Loess Plateau, China. Catena 99:26-33

Wu X, Yao Z, Brüggemann N, Shen Z, Wolf B, Dannenmann M, Zheng X, Butterbach-Bahl K (2010) Effects of soil moisture and temperature on $\mathrm{CO}_{2}$ and $\mathrm{CH}_{4}$ soil-atmosphere exchange of various land use/cover types in a semi-arid grassland in Inner Mongolia, China. Soil Biol Biochem 42:773-787

Xing X, Xu X, Zhang X, Zhou C, Song M, Shao B, Ouyang H (2010) Simulating net primary production of grasslands in northeastern Asia using MODIS data from 2000 to 2005. J Geogr Sci 20(2):193-204

Yao XL, Fu BJ, Lü YH, Sun FX, Wang S, Liu M (2013) Comparison of four spatial interpolation methods for estimating soil moisture in a complex terrain catchment. PLoS ONE 8(1):e54660

Yu D, Shi P, Shao H, Zhu W, Pan Y (2009) Modelling net primary productivity of terrestrial ecosystems in East Asia based on an improved CASA ecosystem model. Int J Remote Sens 30:4851-4866
Zhang N, Liang YM (2002) Studies on the below-ground/aboveground biomass ratio of natural grassland in loess hilly region. Acta Pratacult Sin 11(2):72-78

Zhang XB, Shangguan ZP (2005) The bio-cycle patterns of nutrient elements and stand biomass in forest communities in hilly loess regions. Acta Ecol Sin 25(3):527-537

Zhang K, Dang H, Tan S, Cheng X, Zhang Q (2010) Change in soil organic carbon following the 'Grain-for-Green' programme in China. Land Degrad Dev 21:13-23

Zhang C, Liu GB, Xue S, Sun C (2013) Soil organic carbon and total nitrogen storage as affected by land use in a small watershed of the Loess Plateau, China. Eur J Soil Biol 54:16-24

Zhao T, Luo Y (2008) Spatial patterns of ecosystem carbon residence time and NPP-driven carbon uptake in the conterminous United States. Global Biogeochem Cycles 22:GB3032

Zhu W, Pan Y, He H, Yu D, Hu H (2006) Simulation of maximum light use efficiency for some typical vegetation types in China. Chin Sci Bull 51:457-463 